\title{
Article \\ Study on Adsorption Behavior of Nickel Ions Using Silica-Based Sandwich Layered Zirconium-Titanium Phosphate Prepared by Layer-by-Layer Grafting Method
}

\author{
Chunmin $\mathrm{Li}^{1, *}$, Jinsheng Zhao ${ }^{1}$ and Yusheng Zhang ${ }^{2}$ \\ 1 College of Chemistry and Chemical Engineering, Liaocheng University, Liaocheng 252000, China; \\ zhaojinsheng@lcu.edu.cn \\ 2 CAS Key Laboratory of Nuclear Materials and Safety Assessment, Institute of Metal Research, Chinese \\ Academy of Sciences, Shenyang 110016, China; yshzhang19b@imr.ac.cn \\ * Correspondence: 15296576429@163.com; Tel.: +86-152-9657-6429
}

check for

updates

Citation: Li, C.; Zhao, J.; Zhang, Y. Study on Adsorption Behavior of Nickel Ions Using Silica-Based

Sandwich Layered

Zirconium-Titanium Phosphate Prepared by Layer-by-Layer Grafting Method. Nanomaterials 2021, 11, 2314 https://doi.org/10.3390/

nano11092314

Academic Editor: Vincenzo Vaiano

Received: 4 August 2021

Accepted: 31 August 2021

Published: 6 September 2021

Publisher's Note: MDPI stays neutral with regard to jurisdictional claims in published maps and institutional affiliations.

Copyright: (c) 2021 by the authors. Licensee MDPI, Basel, Switzerland. This article is an open access article distributed under the terms and conditions of the Creative Commons Attribution (CC BY) license (https:/ / creativecommons.org/licenses/by/ $4.0 /)$.

\begin{abstract}
In this study, the composite of silica-based sandwich-layered zirconium-titanium phosphate was prepared by a layer-by-layer grafting method and its adsorption properties in a diluted solution of Ni ions were specifically researched by the bath experiment method. The field-emission scanning electron microscope (FESEM) results presented the smooth surface morphology of the pristine adsorbent and a rough surface morphology of the adsorbed adsorbent and the energy dispersive analysis (EDS) results ensured the presence of the original metal element ( $\mathrm{Si}, \mathrm{O}, \mathrm{Ti}, \mathrm{P}, \mathrm{Zr}$ ) and the captured nickel element on the adsorbent. The Fourier transformed infrared spectroscopy (FTIR) revealed the new band formation of -Si-Ti-O-, -Si-Ti-O-P-, and -Si-Ti-O-P-Zr-O-, which ensured the successful modification of the silica substrate by zirconium-titanium phosphate. The specific surface area and pore size distribution analysis indicated that the pore structure was changed from type-IV to H2-type and the specific surface area (BET) of the modified composite was $337.881 \mathrm{~m}^{2} / \mathrm{g}$. In the bath experiment, the optimal $\mathrm{pH}$ for adsorbing $\mathrm{Ni}$ ions on the composite was $\sim 8$ with the equilibrium time $30 \mathrm{~min}$ at room temperature and the maximum sorption amount was $50.1 \mathrm{mg} / \mathrm{g}$. The adsorption kinetics of the sorption process were corresponded to the pseudo-second-order kinetic equation and the isothermal adsorption data were fitted well to the Redlich-Peterson Model. Thermodynamic simulation results revealed the species of $\mathrm{Ni}$ ions and provided a reasonable $\mathrm{pH}$ scope for better removal of the $\mathrm{Ni}$ element in wastewater.
\end{abstract}

Keywords: silica substrate; Ni adsorption; zirconium-titanium phosphate; thermodynamic simulations

\section{Introduction}

Heavy-metal ions at dilute concentrations widely exist in the environment, mainly from the drainage of industrial sewage. Dilute concentration heavy-metal ions, namely, the content of heavy-metal ions in the industrial wastewater are below ppm grade. This concentration can cause permanent harm to human body and the environment ecology because any physical and chemical method or microbial processing cannot degrade heavymetal ions and just change its existent form [1]. Although the content of heavy-metal in some water bodies is within a certain safe range (the concentrations of total Ni (TNi) must be less than $0.1 \mathrm{mg} \mathrm{L}^{-1}$ in China [2]), it could accumulate in plants and animals in liquid phase and cause permanent damage. Wastewater containing low-level heavy $\mathrm{Ni}^{2+}$ has a great and far-reaching impact on the environment and has caused indelible harm to plants and animals [3,4]. Therefore, it is strategically and ecologically urgent to accelerate research on the treatment of low-concentration $\mathrm{Ni}^{2+}$ in solution.

The sorption processes are well known to be an efficient way to remove heavy metals particularly in these dilute systems, which provide the most important processes controlling contaminant mobility in the environment [5]. Many articles using organic or 
inorganic adsorbents have been reported, such as metal-organic frameworks [6-8], clays [9], zeolites [10], birnessite [11], modified activated carbon [12], gallocyanine-grafted hydrogel [13], nanoporous polymers [14], $\mathrm{Fe}_{3} \mathrm{O}_{4}$ particles [15], $\mathrm{Ni}_{0.8} \mathrm{~K}_{0.2} \mathrm{Fe}_{2} \mathrm{O}_{4}$ nanomaterials [16], and so on. However, corrosion and mechanical stability problems are normally found in the organic adsorbents while narrow $\mathrm{pH}$ applications and low ion selectivity often exist in metal oxide adsorbent [17]. Furthermore, besides the surface properties of the adsorbent and the environment of the aqueous solution, most relevant retention mechanism studies did not take the existent form of heavy-metal ions into consideration as the metal nature which includes complex cations, free cations, free oxyanions [18], or the formation of precipitates at the interface as hydroxides or insoluble oxides [19], which is one of the most important aspects affecting the removal style. It is well known that trace-level adsorption (ion-exchange) is often completely different compared with macro-level processes. Therefore, thoroughly exploring the key controlling parameters and the retention mechanism in more dilute systems could be favorable to develop accurate sorption models which can effectively predict the transport and fate of the environmental heavy-metal ions and achieve a more in-depth understanding of sorption process.

Tetravalent metal phosphate with the general formula $\mathrm{M}(\mathrm{IV})\left(\mathrm{HPO}_{4}\right)_{2} \cdot \mathrm{nH}_{2} \mathrm{O}$, where $\mathrm{M}(\mathrm{IV})$ could be $\mathrm{Zr}$, Ti, Sn, Ce, Th, etc., possess great properties in the applications of adsorption, ion exchange [20], catalysis [21], proton conduction [22], and so on. For example, titanium phosphate (TiP) and zirconium phosphate $(\mathrm{ZrP})$ with excellent adsorption amounts, abundant $-\mathrm{P}-\mathrm{OH}$ or $-\mathrm{OH}$ group active sites, and special layered structures with a hexagonal shape are widely known as suitable adsorbents or ion exchangers to remove heavy metal ions from aqueous solutions [23]. Although many specially designed structures of metal phosphate for removing target metal ions have been developed [24-27], their superiorities are constrained by small surface areas, small pores, and interlayer spaces caused by the cluster formation. Besides, tetravalent metal phosphates containing single-metal cation are inferior to those compounds containing two different anions and a cation in aspects of sorption or exchange properties and selectivity for target hazard ions [20]. However, little work has been carried out to research metal phosphates with two cations, which may be more advantageous to remove specific hazard ions. Although, some articles have reported zirconium titanium phosphate and evidenced better potential for this material to be used as a cation exchanger than monometallic phosphate, reporting the replacement of zirconium with titanium or titanium with zirconium in phosphate structure [28]. Hence, the morphological control of a Ti-Zr adsorbent with the assistance of reliable support may enhance the adsorption performance of adsorbent [2,29]. To the best to our knowledge, there are hardly any articles reporting the preparation of polymetallic phosphate-containing multilayer structure with each layer containing different structural metal atoms. Based on the abovementioned, loading polymetallic phosphate one layer at a time onto suitable carriers at the molecular level to form composite adsorbents or ion exchangers will be a very promising prospect in the disposal of heavy-metal ions.

SBA-15 is a kind of mesoporous molecular sieve. It has wide application prospects in the fields of catalysis, separation, biology, and nano materials. Based on its advantages of high hydrothermal stability, large surface area, and abundant surface hydroxyl groups, it has opened up a new research field for catalysis, adsorption separation, and advanced inorganic materials. Besides, it was also used as a support to make the composites more stable [30]. In this work, SBA-15 was chosen as the silica-based substrate according to its abundant $-\mathrm{OH}$ modified sites. The developed layer-by-layer method was adopted, which could allow for a better control of the alternating layers of zirconium titanium phosphate on SBA-15 at the molecular level and form high-k dielectric materials with lower porosity [31]. The rationale behind our choice of precursors for surface modification is based on the fact that $\mathrm{Ti}(\mathrm{OPri})_{4}, \mathrm{Zr}(\mathrm{OPri})_{4}$ and $\mathrm{POCl}_{3}$ can be used as suitable "acid-based" pair precursors for the synthesis of zirconium titanium phosphate [30]. The structure of the synthesized composites, the adsorption behavior of heavy metal ions, and the adsorption mechanism were studied in detail in this work. The novel silica-based zirconium titanium 
phosphate adsorbent with alternating layers showed good application prospects in the low-concentration heavy-metal ions removing process.

\section{Material and Methods}

\subsection{Materials}

The SBA-15 was synthesized according to reference [31]. Analytical grade zirconium propoxide was obtained from Shanghai Macklin Biochemical Co., Ltd. (Shanghai, China; Purity: $70 \omega t \%$ in 1-propanol). Analytical grade titanium isopropoxide (Beijing, China; Purity: $99.9 \%$ metals basis) was purchased from Alfa Aesar Co., Ltd. Analytical grade phosphorous oxide trichloride (Purity: 95\%) was purchased from Sinopharm Group Chemical Reagent Co., Ltd. (Guangzhou, China). Analytical grade $\mathrm{KCl}$ (Purity: $95 \omega t \%), \mathrm{MgCl}_{2}(\mathrm{Pu}-$ rity: $99.5 \omega t \%), \mathrm{CaCl}_{2}$ (Purity: $96 \omega \mathrm{t} \%$ ), $\mathrm{Ni}\left(\mathrm{NO}_{3}\right)_{2}$ (Purity: $98 \omega \mathrm{t} \%$ ), $\mathrm{HCl}$ (Purity: $38 \omega t \%$ ) and $\mathrm{NaOH}$ (Purity: $98 \omega t \%$ ) were all obtained from Guangzhou Jinhua Da Chemical Reagent Co., Ltd. (Guangzhou, China). MilliQ water was used throughout the experiments (electric conductivity: 0.055 us $/ \mathrm{cm}$ ).

\subsection{Material Synthesis Process}

As shown in Figure 1, the synthetic procedure of the adsorbent was as follows. Step 1: The SBA-15 silica-based substrate was impregnated for $20 \mathrm{~min}$ at $80^{\circ} \mathrm{C}$ in a piranha solution (a mixture of concentrated sulfuric acid and 30\% hydrogen peroxide (7:3)) in order to clean the surface and generate a well-producible oxide layer. After the treatment, SBA-15 was filtered by suction filtration and washed four times by water. Step 2: $1 \mathrm{~g}$ of the pretreatment SBA-15 was added into a three-neck flask with two glass stoppers and $20 \mathrm{~mL}$ of anhydrous toluene and $3.4 \mathrm{mmoL}$ titanium isopropoxide were added into the flask. Step 3: After sealing with two glass stoppers and a condenser pipe, the flask was refluxed with vigorous stirring under an oil bath for $2 \mathrm{~h}$ at $110^{\circ} \mathrm{C}$. The filtered sample noted as Si-Ti was washed three times by anhydrous toluene and three times with deionized water for hydrolysis. The sample was dried in a drying oven at $80{ }^{\circ} \mathrm{C}$ for $24 \mathrm{~h}$. Step 4: The dried sample Si-Ti was then reacted with $10.2 \mathrm{mmoL}$ phosphorus oxychloride by the same procedure above and the reacted production was noted as Si-Ti-P. Step 5: The sample noted as Si-Ti-P finally reacted with $3.4 \mathrm{mmoL}$ zirconium propoxide solution by repeating the same procedure and the final adsorbent was noted as Si-Ti-P-Zr.

\subsection{Characterization Methods}

Fourier-transformed infrared spectroscopy (FTIR) of the samples was recorded from $400-4000 \mathrm{~cm}^{-1}$ to evidence the formation of the main functional groups before adsorption and the new metal-chemical bond after adsorption (Ramsey, MN, USA). The crystalline phase of the samples was analyzed by X-ray diffraction instrument (XRD), in which Nifiltered $\mathrm{Cu}-\mathrm{K} \alpha$ radiation were analyzed with a scanning rate of $8^{\circ} / \mathrm{min}$ from 10 to $60^{\circ}$ and a step size of $0.02^{\circ}$ (SMARTLAB3KW, Tokyo, Japan). The morphology analysis of the adsorbent before and after adsorption was examined by the field-emission scanning electron microscope (FE-SEM), (Hitachi SU8220, Tokyo, Japan). The elemental content of the adsorbent before and after adsorption was analyzed using energy dispersive analysis (EDS, EDAX PV8200, Tokyo, Japan). The lattice structure of the sample was analyzed by Spectra S/TEM type transmission electron microscopy (TEM) (Spectra S, Amsterdam, Netherlands). The sample thickness was less than $1 \mathrm{~mm}$ and the acceleration voltage was $300 \mathrm{kV}$. The specific surface area (BET) and pore distribution of Si-Ti-P, Si-Ti-P, and Si-Ti-P-Zr were measured by the surface area and porosity instrument with $\mathrm{N}_{2}$ adsorption and desorption methods (Micromeritics TriStar II, New York, NY, USA). 


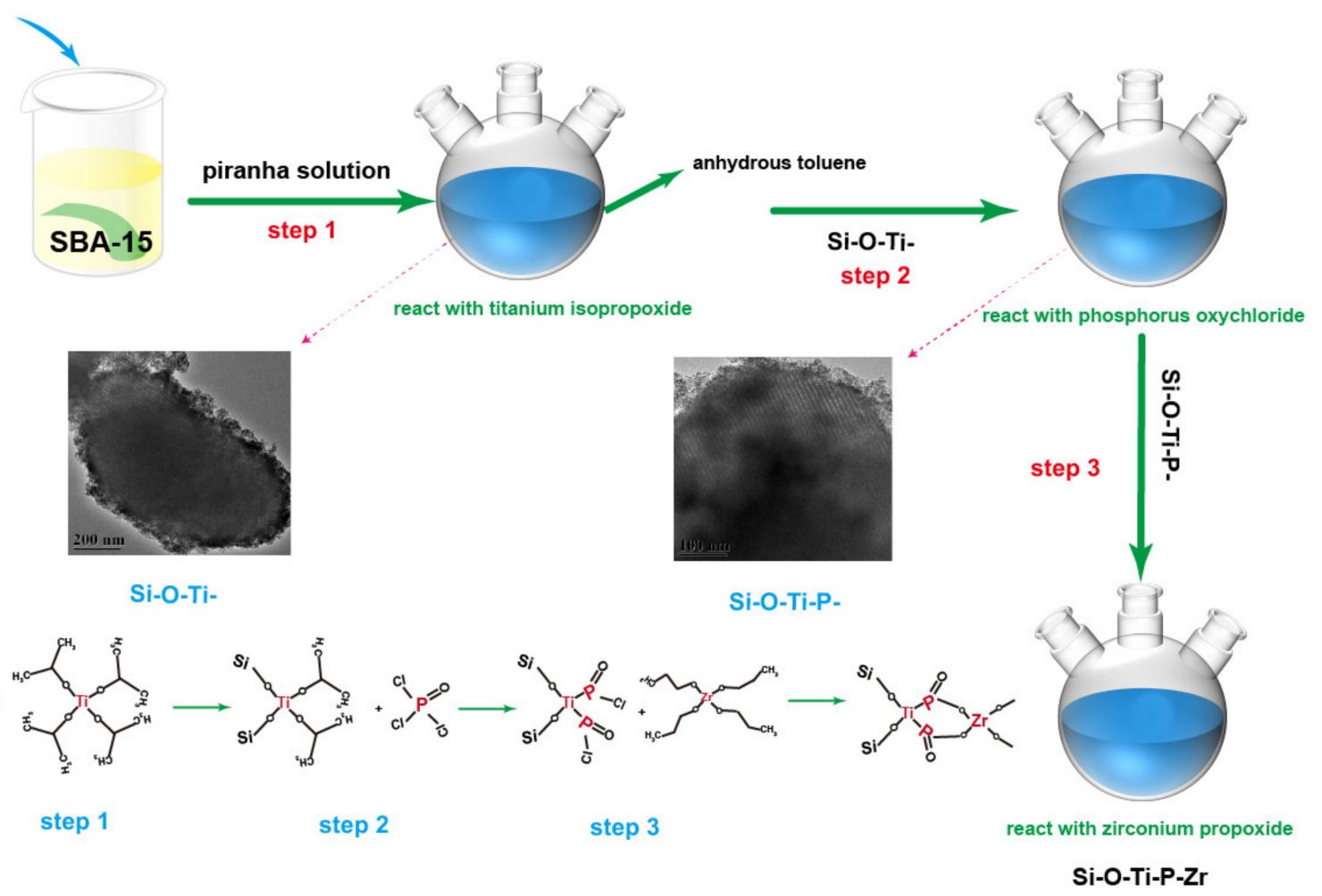

Figure 1. Synthesis process of the adsorbent.

\section{4. $\mathrm{Ni}^{2+}$ Adsorption Experiment on $\mathrm{Zr}$-P-Ti-Si in Batch Experiment}

Typical adsorption experiments of the $\mathrm{Ni}$ ions were conducted as follows: $0.5 \mathrm{~g}$ of the nitrate of heavy metal ions was dissolved into $500 \mathrm{~mL}$ ultrapure water, forming $500 \mathrm{ppm}$ stock solution. The diluted solutions were obtained by adjusting the stock solution to the following experiments requiring different concentrations of heavy metal solutions; $0.05 \mathrm{~g}$ of the silica-based zirconium titanium phosphate powder was added into $50 \mathrm{~mL}$ of $500 \mathrm{ppm} \mathrm{Ni}$ ions solution in the polyethylene tube, and then the capped tub was shaken at table concentrator with $100 \mathrm{rpm}$ for $24 \mathrm{~h}$ at room temperature to reach equilibrium. The adsorbed material was separated by a centrifuge at $8000 \mathrm{rpm}$ and respectively washed three times by pure water and ethyl alcohol, then dried in a drying oven at $80^{\circ} \mathrm{C}$. The supernatant was again filtered by drainage pin-type filter $(0.45-\mu \mathrm{m}$ diameter) and the concentration of the metal ions in the filtered solution was measured using Graphite Furnace Atomic Absorption Spectrometry (GFAAS), (AA-700, Shimadzu, Kyoto, Japan) for low concentrations (ppb grade). The adsorption capacity, the distribution coefficient, and the removal efficiency were calculated by the following Equations [32,33]:

$$
\begin{aligned}
q & =\left(V\left[C_{0}-C_{F}\right]\right) / m \\
K_{d} & =V\left[\frac{\left(C_{0}-C_{f}\right)}{C_{f}}\right] / m \\
R \% & =100 \times\left(C_{0}-C_{f}\right) / C_{0}
\end{aligned}
$$

where $q(\mathrm{mg} / \mathrm{g})$ is the adsorption capacity of the silica-based zirconium titanium phosphate; $K_{d}(\mathrm{~mL} / \mathrm{g})$, used for the determination of the affinity and selectivity of the compounds for different metal ions; $R \%$ represents the removal efficiency; $C_{0}(\mathrm{mg} / \mathrm{L})$ is the initial concentration of the heavy metal ions; $C_{f}(\mathrm{mg} / \mathrm{L})$ is the residual concentration of the metal ions in solution. 


\subsubsection{The Effect of the Initial Concentration of $\mathrm{Ni}$ Ions on the Sorption Process}

The study on the various concentrations $(0-250 \mu \mathrm{g} / \mathrm{L})$ of $\mathrm{Ni}$ ions was carried out using batch method with a solid/liquid ratio of $1 \mathrm{~g} / \mathrm{L}(0.1 \mathrm{~g} / 0.1 \mathrm{~L})$, contact time $24 \mathrm{~h}, \mathrm{pH}=8$, and at room temperature. The residual concentration of $\mathrm{Ni}$ ions was filtered and measured by GFAAS.

\subsubsection{The Effect of Contact Time on the Sorption Process}

The kinetic study was conducted by dispersing $0.1 \mathrm{~g}$ of the adsorbent into $100 \mathrm{~mL}$ solutions with the heavy metal concentrations of $60 \mu \mathrm{g} / \mathrm{L}$ and the contact time range from 0-120 min (sampling time point: 2, 5, 10, 20, 30, 60, 90, $120 \mathrm{~min}$ ). The $\mathrm{pH}$ of the solution was 8 and the adsorption process was conducted at room temperature. The suspensions were filtered at the various reaction times, and the filtrates were analyzed by GFAAS.

\subsubsection{The Effect of $\mathrm{pH}$ on the Sorption Process}

The effect of $\mathrm{pH}$ on the adsorption process was measured by dispersing $0.1 \mathrm{~g}$ of the adsorbent into $100 \mathrm{~mL}$ solutions with the heavy metal concentrations of $60 \mu \mathrm{g} / \mathrm{L}$, and the $\mathrm{pH}$ scope of the solution ranged from 1 to 14 and was adjusted by $1 \mathrm{M} \mathrm{HCl}$ and $1 \mathrm{M} \mathrm{NaOH}$ solution and sodium hydroxide solution; then, the capped tubes were shaken at $100 \mathrm{rpm}$ for $3 \mathrm{~h}$ to reach adsorption equilibrium at room temperature. All the suspensions were filtered and analyzed by GFAAS.

\subsubsection{Thermodynamic Simulations of the Hydrolyzed Species of Ni Ions}

The solution $\mathrm{pH}$ caused the hydrolyzed species and the complete precipitation of the heavy metal ions, which affects the adsorption process on the adsorbent. To understand the adsorption behavior of heavy metal ions on the adsorbent, thermodynamic simulations were utilized to reveal the existent form of heavy metal ions in various $\mathrm{pH}(1-14)$ solutions. The thermodynamic calculations were carried out with Matlab ${ }^{\circledR} \mathrm{R} 2010$ a software using thermodynamic parameters of all possible reactions to simulate the possible species of heavy metal ions including metals ions and metal ion complexes. Equations (4)-(7) were used to calculate the species distribution of $\mathrm{Ni}$ ions at different $\mathrm{pH}$ values. These simulation results together with experimental results facilitate the understanding of adsorption mechanism. The adsorption experiments were conducted at specific $\mathrm{pH}$ values which possess the specific hydrolyzed species of $\mathrm{Ni}$ ions. The adsorbed material was separated by filtration and analyzed.

Chemical reaction of Nickel hydroxide species at different $\mathrm{pH}$ values (all the data were obtained from HSC 6.0 database):

$$
\begin{gathered}
\mathrm{Ni}^{2+}+\mathrm{OH}^{-} \rightarrow \mathrm{NiOH}^{+} \mathrm{Ksp}=4.97 \\
\mathrm{Ni}^{2+}+2 \mathrm{OH}^{-} \rightarrow \mathrm{Ni}(\mathrm{OH})_{2} \mathrm{Ksp}=8.55 \\
\mathrm{Ni}^{2+}+2 \mathrm{OH}^{-} \rightarrow \mathrm{Ni}(\mathrm{OH})_{2}(\mathrm{~s}) \mathrm{Ksp}=16.96 \\
\mathrm{Ni}^{2+}+3 \mathrm{OH}^{-} \rightarrow \mathrm{Ni}(\mathrm{OH})^{3-} \mathrm{Ksp}=11.33
\end{gathered}
$$

\subsubsection{The Affinity Measurement toward Ni Ions}

To measure the selectivity property toward Ni ions of the adsorbent, the counter ions such as $\mathrm{K}, \mathrm{Mg}$, and $\mathrm{Ca}$, which largely existed in wastewater and make strong competitors for the adsorption sites in many adsorbents, were selected. The distribution coefficient $K_{d}$ was used for test the affinity of the adsorbent for $\mathrm{Ni}$ ions and the equation is given in Equation (3).

The selectivity test was conducted using mixed solutions with $50 \mathrm{~mL} 0.5 \mathrm{mmol} \mathrm{L}^{-1}$ of $\mathrm{K}, \mathrm{Mg}$, and $\mathrm{Ca}$ ions and $60 \mathrm{ug} \mathrm{L}^{-1}$ of $\mathrm{Ni}$ ions at room temperature and the $\mathrm{pH}$ of the solution was adjusted to about 8 using $1 \mathrm{M} \mathrm{NaOH}$ solution. The dosage of the adsorbent was $0.06 \mathrm{mg}$ and the contact time was $2 \mathrm{~h}$ to ensure sorption equilibrium. 


\section{Results and Discussion}

\subsection{Characterization Analysis}

\subsubsection{TEM Analysis of the SBA-15 and $\mathrm{SiO}_{2}-\mathrm{Ti}-\mathrm{P}-\mathrm{Zr}$ Adsorbent}

In order to characterize the morphology of the composite, TEM characterization of SBA-15 support and final $\mathrm{SiO}_{2}-\mathrm{Ti}-\mathrm{P}-\mathrm{Zr}$ adsorbent was illustrated in Figure 2. From Figure $2 \mathrm{a}$, we can see that the SBA-15 support processed no layer structure before loading the functional materials, which corresponds to the magnified image in Figure 2a-1. Compared with SBA-15 support, Figure 2b, which represents the cross-section image of the adsorbent, shows the layer-by-layer shape and there is a clear boundary between functional materials and SBA-15 support shown in Figure 2b-1. Specific interlayer width is described in Figure 2c. From Figure 2c-1, we can see that the width of -Ti-O-P- layer was about $11.38 \mathrm{~nm}$ while the width of -P-Zr-O- layer was about $7.25 \mathrm{~nm}$. Therefore, the width of one constitutional unit of the adsorbent was $18.63 \mathrm{~nm}$. EDS analysis indicated that molar ratio of the element (Ti: O: P: Zr) on the surface of the adsorbent was 9.14: 59.15: 15.44: 1.54. According to the measurement and calculation of the nanoscale structure in the HRTEM image, the Si-Ti-P-Zr lamellar structure effectively grew on the Si-based support.
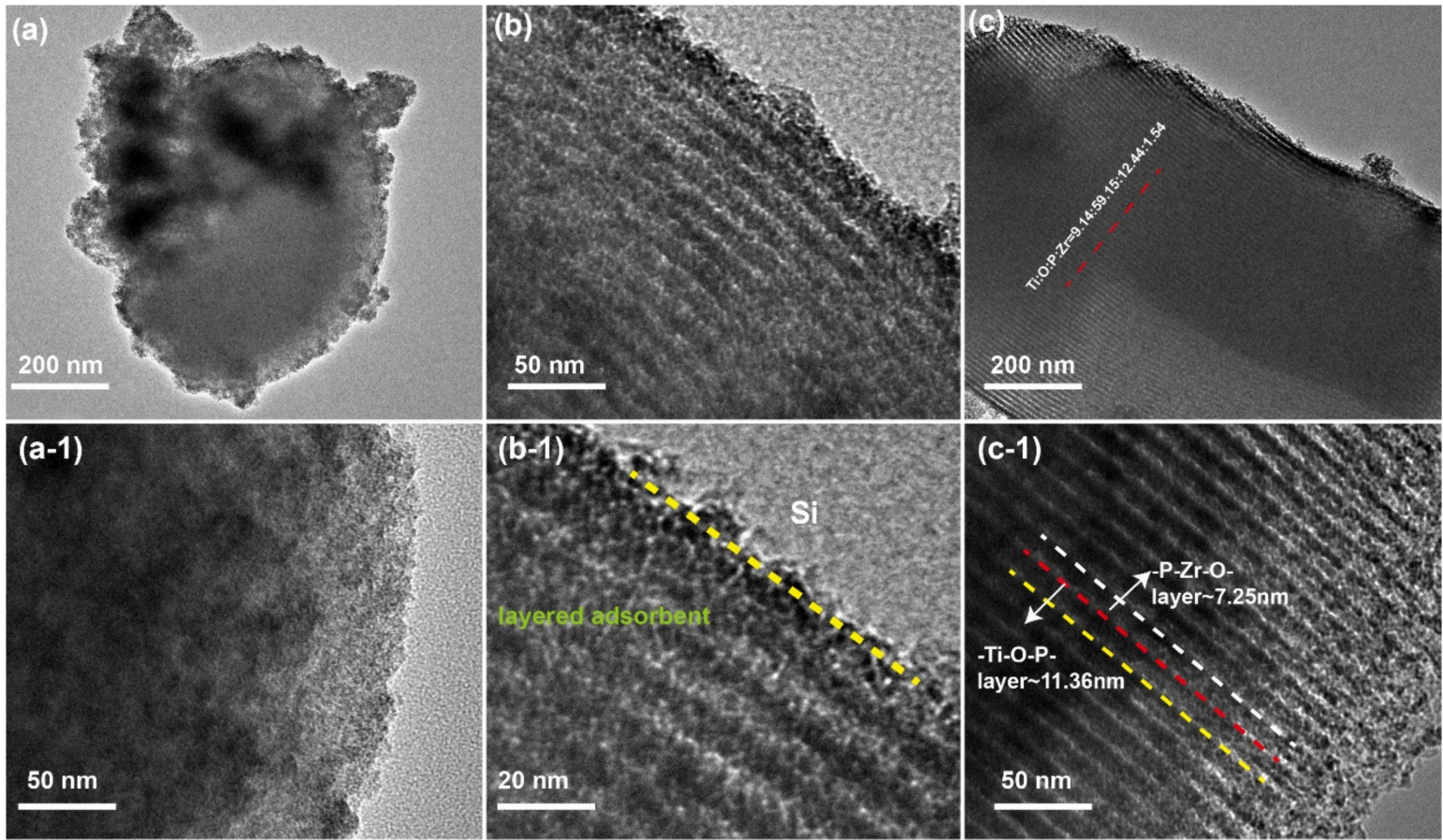

Figure 2. TEM micrograph of (a) the SBA-15 and (a-1) magnified image of SBA-15, (b) cross-section image of $\mathrm{SiO}_{2}-\mathrm{Ti}-\mathrm{P}-\mathrm{Zr}$ adsorbent, (b-1) magnified image of cross-section image, (c) the $\mathrm{SiO}_{2}-\mathrm{Ti}-\mathrm{P}-\mathrm{Zr}$ adsorbent, and (c-1) the magnified image of $\mathrm{SiO}_{2}-\mathrm{Ti}-\mathrm{P}-\mathrm{Zr}$ adsorbent.

\subsubsection{The FT-IR and XRD Analysis of the Formation Process of the Adsorbent}

The FT-IR analysis of the formation process of the adsorbent including $\mathrm{SiO}_{2}, \mathrm{SiO}_{2}-\mathrm{Ti}$, $\mathrm{SiO}_{2}-\mathrm{Ti}-\mathrm{P}$, and $\mathrm{SiO}_{2}-\mathrm{Ti}-\mathrm{P}-\mathrm{Zr}$ is illustrated in Figure 3a. The peaks at 3446 and $1663 \mathrm{~cm}^{-1}$ respectively corresponded to the antisymmetric and symmetric stretching vibrations of -OH groups in water [34]. The peak at $1090 \mathrm{~cm}^{-1}$ was attributed to the representation of antisymmetric vibration of Si-O-Si [35], and peaked at around 793, 966, and $470 \mathrm{~cm}^{-1}$, responding to symmetrical stretching vibration of Si-O [35]. As elucidated in Figure 3a, the peak at $793 \mathrm{~cm}^{-1}$ gradually disappeared as the synthesis process progressed from Si-Ti to Si-Ti-P-Zr, which indicated that the Si-O bonds acted as active sites bonding to the raw materials in the synthesis process. Based on previous report, the peak of $\mathrm{O}=\mathrm{P}$ band should be around $1006 \mathrm{~cm}^{-1}[36,37]$ which caused a wider and larger peak around $1090 \mathrm{~cm}^{-1}$ in 
Si-Ti-P, indicating that the peak of O-P was merged with the peak of Si-O-Si. These bands indicate the presence of structural hydroxyl groups/protonic sites in the material.
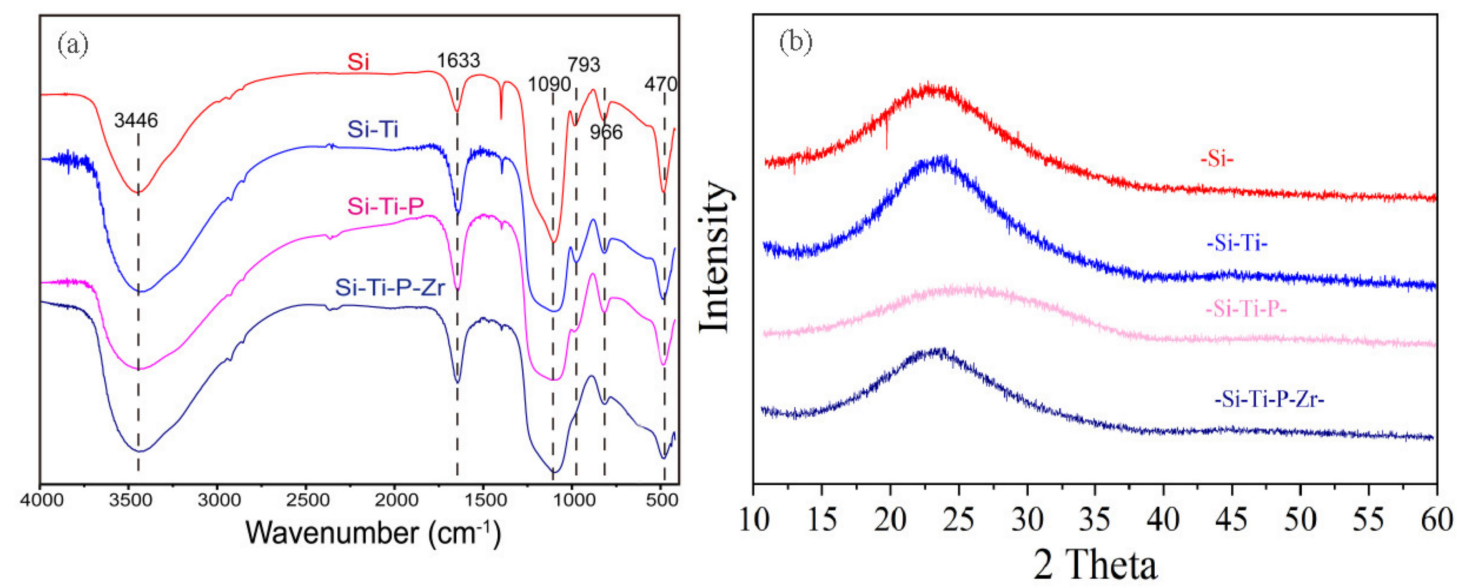

Figure 3. The (a) FT-IR and (b) XRD analysis of the formation process of the adsorbent (SBA-15, Si-Ti, Si-Ti-P, and Si-Ti-P-Zr).

The schematic diagram of the XRD of the adsorbent during the synthesis process is described in Figure $3 b$. No diffraction peaks were obtained either in the intermediate product or the final product, which indicated the amorphous structure existed during the whole synthesis process. Based on our previous study [38], adsorbent with amorphous structure exhibited a satisfactory metal adsorption. Herein, the amorphous structure of the adsorbent may be a significant factor for the better adsorption property of $\mathrm{Ni}$ ions.

\subsubsection{The Specific Surface Area and Pore Size Distribution Analysis}

The isotherm curve obtained from adsorption-desorption of nitrogen and the pore volume were performed to identify the hole type of the modified porous materials, which are described in Figure 4. The result indicates that the BET and pore volume gradually decreased in the modification process, while the average pore diameter hardly changed in the process. The $\mathrm{BJH}$ model was used to analyze the desorption curve of the different materials. As shown in Figure $4 a-d$, four kinds of materials exhibited a representative type-IV adsorption behavior, which illustrates a strong force between the material and nitrogen. In Figure 4a, a narrow H1-type hysteresis loop appeared at a relative pressure between 0.7 and 1 due to the capillary coagulation. This indicated the sample mesoporous was ordered. In Figure $4 b-d$, the modified samples are shown to have had a broad H2-type at a relative pressure between 0.4 and 1 , which was attributed to the porous adsorption and uniform particle packing hole. The transformation of the hysteresis loop type reveals the existence of mesoporosity and macroporosity. Based on the above analysis, the BET and pore structure of the adsorbent were greatly altered in the modification process. The BET, pore volume, and average pore width data obtained from three fresh samples are listed in Table 1. As shown in Table 1, the BET specific surface area significantly reduced from 566.991 to $337.881 \mathrm{~m}^{2} / \mathrm{g}$, which indicated that the adsorbent effectively grew on the surface of the silica support and reduced the surface area. Additionally, the formation of the adsorbent changed the pore structure of the SBA-15 from type-IV to H2-type. Besides, the pore volume and the average pore width also reduced from $70.787 \AA$ to $66.997 \AA$ through the synthesis process. 

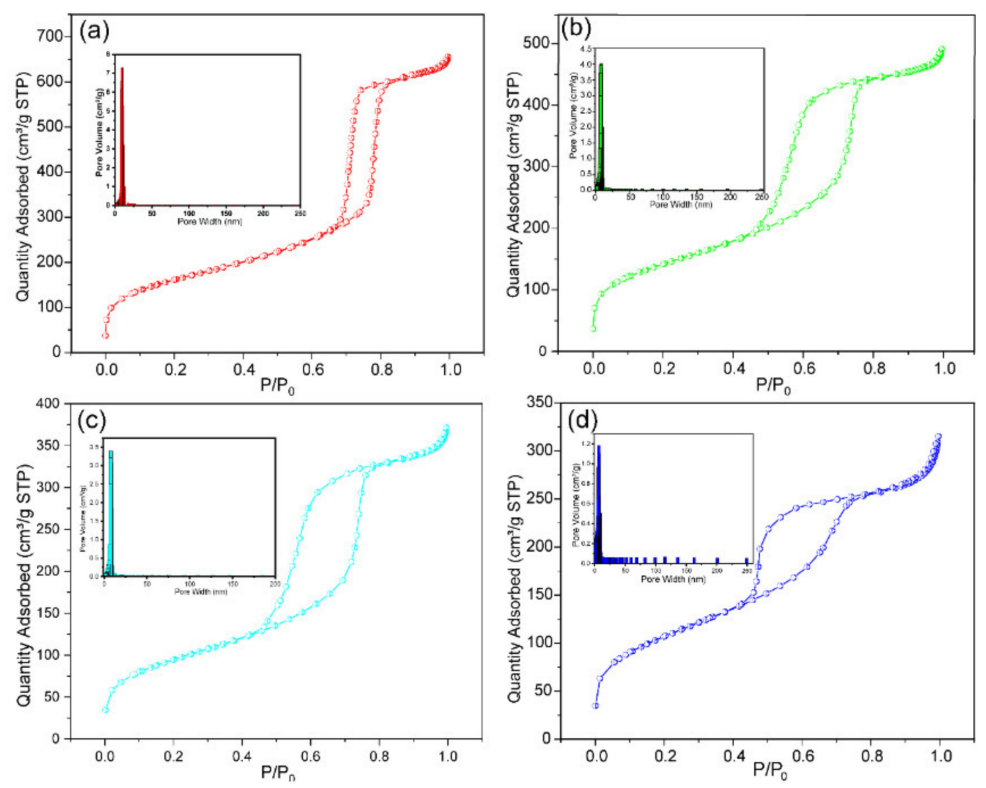

Figure 4. The nitrogen adsorption-desorption isotherm and the pore volume distribution of the samples: (a) SBA-15, (b) Si-Ti, (c) Si-Ti-P, (d) Si-Ti-P-Zr.

Table 1. BET surface area, pore volume, and average pore diameter by BJH adsorption isotherms.

\begin{tabular}{|c|c|c|c|c|c|c|c|c|}
\hline Sample & Si Substrate & (Er.) & Si-Ti & (Er.) & Si-Ti-P & (Er.) & Si-Ti-P-Zr & (Er.) \\
\hline BET Specific Surface Area $\left(\mathrm{m}^{2} / \mathrm{g}\right)$ & 566.991 & 0.011 & 502.598 & 0.401 & 382.295 & 0.295 & 337.881 & 0.119 \\
\hline Pore Volume $\left(\mathrm{cm}^{3} / \mathrm{g}\right)$ & 0.903 & 0.003 & 0.679 & 0.021 & 0.434 & 0.003 & 0.506 & 0.004 \\
\hline Average Pore Width $(\AA)$ & 70.787 & 0.213 & 59.702 & 0.298 & 49.650 & 0.350 & 66.997 & 0.287 \\
\hline
\end{tabular}

3.1.4. The Morphology and Element Mapping Analysis of the Pristine Adsorbent and Adsorbed Adsorbent

The morphology analysis of the pristine adsorbent and adsorbed adsorbent was conducted by FESEM and the results are shown in Figure 5. As presented in Figure 5a, the morphology of the pristine adsorbent was smooth and neat while the adsorbent after adsorbing $\mathrm{Ni}^{2+}$ showed a rough morphology which was caused by the chemical bond formation of -P-O-Ni or -O-Ni on the surface of the adsorbent which was corresponded to the results of FT-IR. The element distribution of the pristine adsorbent and adsorbed adsorbent are shown in Figure 6. Element mapping analysis of the pristine adsorbent and adsorbed adsorbent ensured the presence of the original metal element ( $\mathrm{Si}, \mathrm{O}, \mathrm{Ti}, \mathrm{P}, \mathrm{Zr}$ ) and the captured nickel element. Besides, all the metal elements were homogeneously distributed on the surface of silica substrate. Figure 7 shows the atom percent of the elements. Those results indicated that $\mathrm{O}$ was the dominating element $(74.84 \%)$ which provided abundant hydroxyl adsorption sites for adsorbing $\mathrm{Ni}$ ions. The atom percent of the captured nickel element was $0.33 \%$, which revealed the relative content of $\mathrm{Ni}$ atoms. The reason for the lower content of $\mathrm{Ni}$ atoms may be ascribed to the very low concentration of Ni solutions used throughout the experiment. 

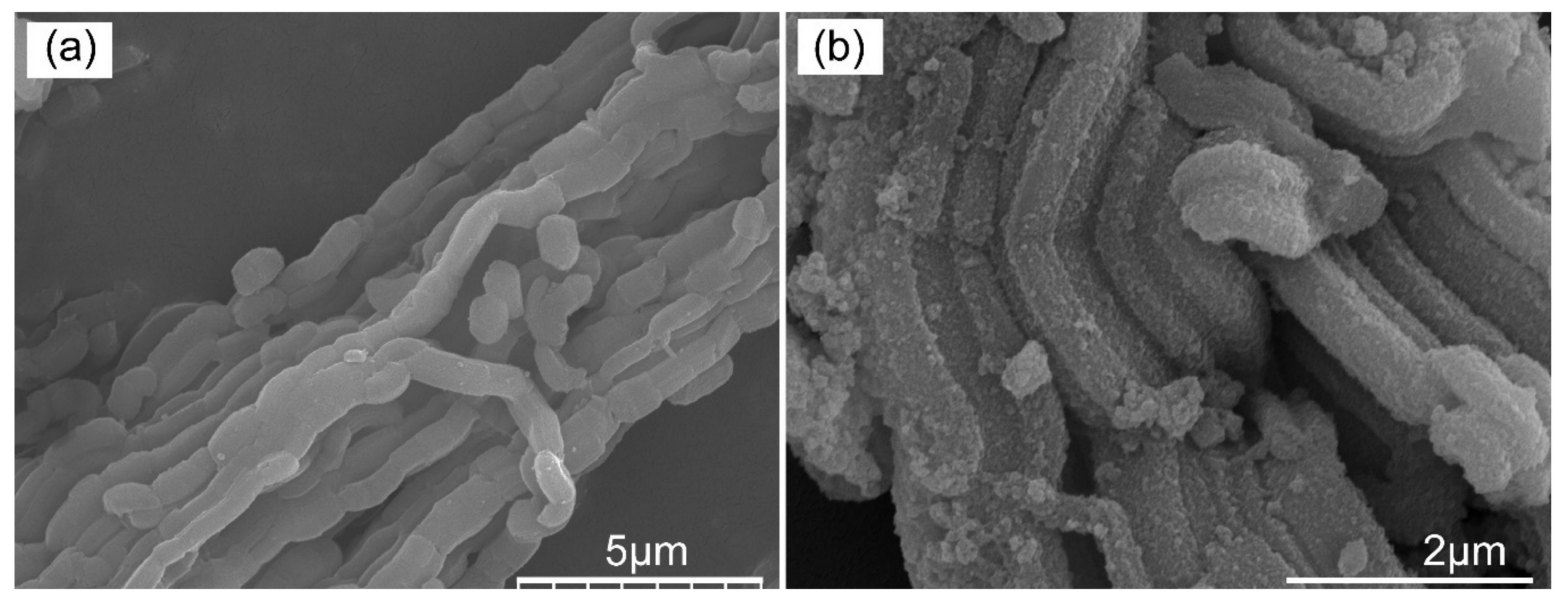

Figure 5. (a) SEM images of the pristine adsorbent and (b) adsorbed adsorbent.
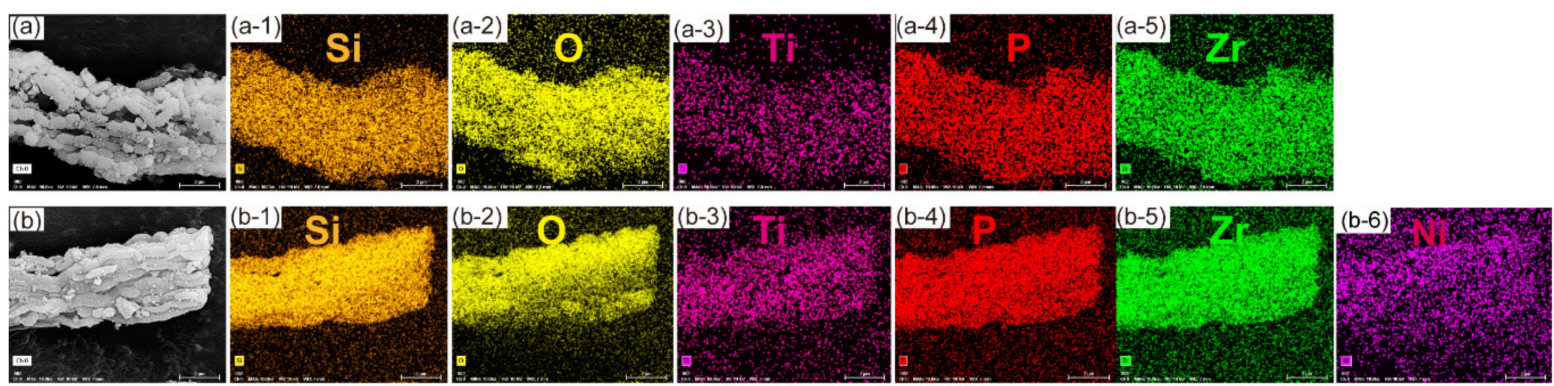

Figure 6. SEM images and EDS element-mappings of (a) the pristine adsorbent, (a-1) Si element distribution, (a-2) O element distribution, (a-3) Ti element distribution, (a-4) P element distribution, (a-5) Zr element distribution and (b) the adsorbed adsorbent, (b-1) Si element distribution, (b-2) O element distribution, (b-3) Ti element distribution, (b-4) P element distribution, (b-5) Zr element distribution, (b-6) Ni element distribution.
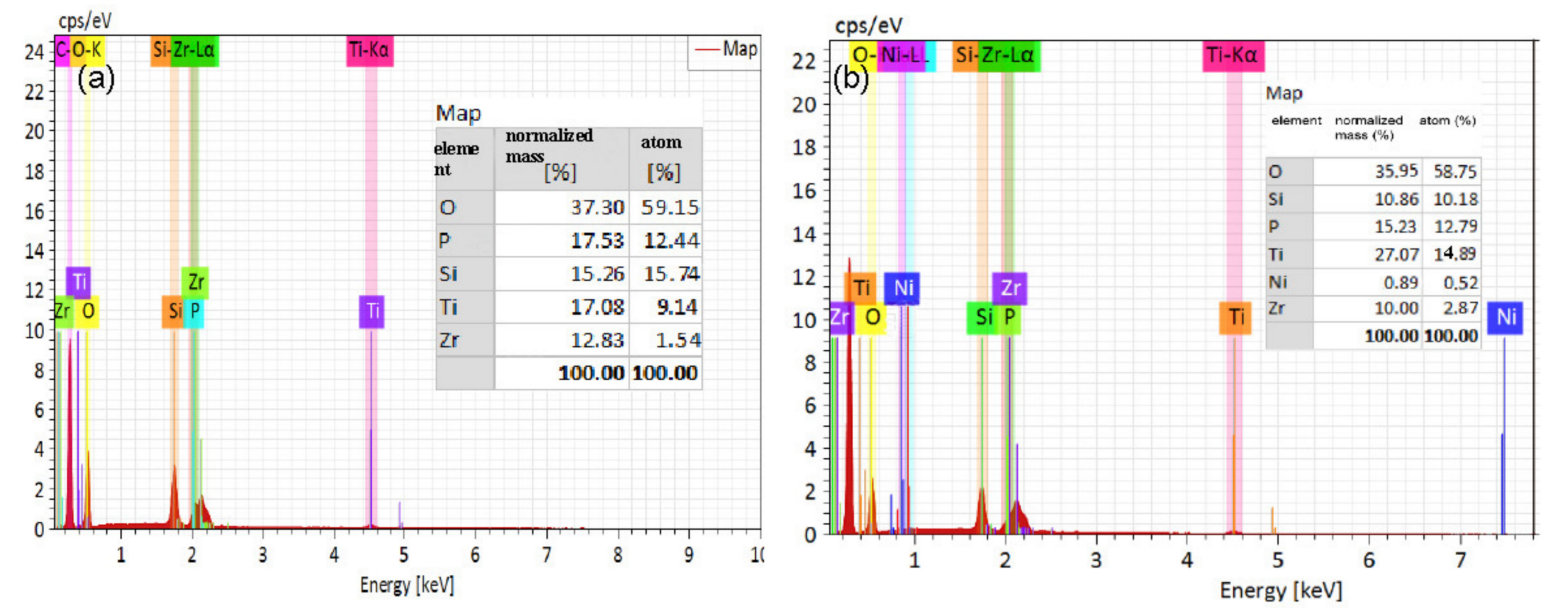

Figure 7. The atom percent of the elements (a) O, P, Si, Ti, $\mathrm{Zr}$ and (b) $\mathrm{Si}, \mathrm{O}, \mathrm{Ti}, \mathrm{P}, \mathrm{Ni}, \mathrm{Zr}$.

\subsection{Analysis of the Hydrolyzed Species of Ni Ions by Thermodynamic Simulations Method}

Figure 8 presents the results of the thermodynamic simulations of the hydrolyzed species of $\mathrm{Ni}$ ions in the $\mathrm{pH}$ value between 1 and 14 . In the $\mathrm{pH}$ region from 1 to 8 , the occupied $\mathrm{Ni}$ species was $\mathrm{Ni}^{2+}$. When the $\mathrm{pH}>8, \mathrm{Ni}^{2+}$ began to reduce and the $\mathrm{Ni}$ species of $\mathrm{NiOH}^{+}$and $\mathrm{Ni}(\mathrm{OH})_{2}(\mathrm{aq})$ started to appear. When the $\mathrm{pH}$ was about 10 , the occupied $\mathrm{Ni}$ species was $\mathrm{Ni}(\mathrm{OH})_{2}(\mathrm{aq})$ while $\mathrm{Ni}(\mathrm{OH})^{3-}$ began to appear and disappeared when the $\mathrm{pH}$ 
was $>13$. The $\mathrm{Ni}$ species started to appear when the $\mathrm{pH}$ was about 9 and always stayed in the solution until the $\mathrm{pH}$ was 14 . These results indicated that the $\mathrm{pH}$ of the solution had a great influence on the hydrolyzed species of $\mathrm{Ni}$ ions, while the concentration of hydrolyzed $\mathrm{Ni}$ ions with more than two hydroxyls was extremely low based on the low Ksp values $\left(8.55\right.$ for $\mathrm{Ni}(\mathrm{OH})_{2}(\mathrm{aq}), 16.96$ for $\mathrm{Ni}(\mathrm{OH})_{2}(\mathrm{~s})$ and 11.33 for $\left.\mathrm{Ni}(\mathrm{OH})^{3-}\right)$. Therefore, the appropriate $\mathrm{pH}$ for studying the sorption of $\mathrm{Ni}$ ranged from 1 to 10 as most $\mathrm{Ni}$ ions may precipitate when the $\mathrm{pH}>10$.

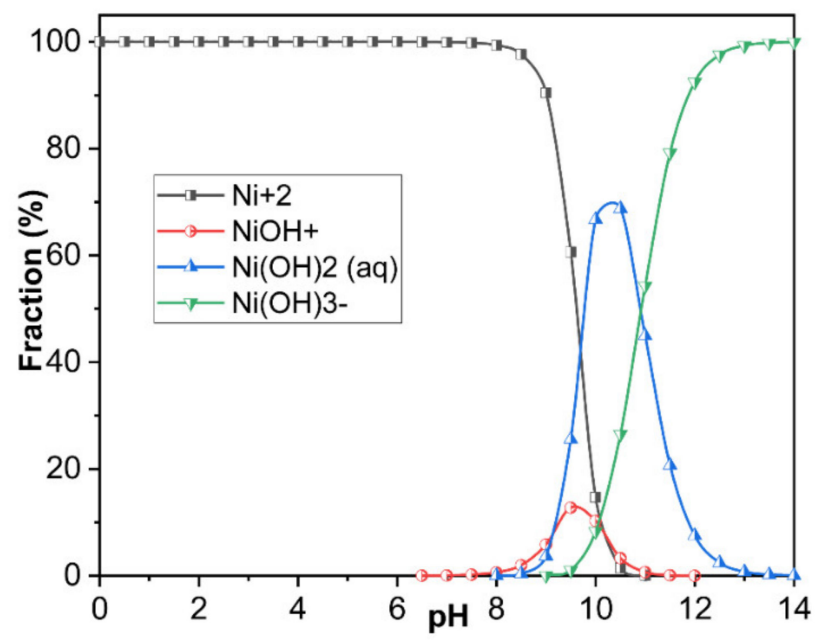

Figure 8. The results of the thermodynamic simulations of the hydrolyzed species of Ni ions in the $\mathrm{pH}$ range from 1 to 14 .

\subsection{Analysis of the Batch Adsorption and Ion Selectivity}

The results obtained from the effect of the initial concentration on the adsorption of $\mathrm{Ni}$ ions on the adsorbent are shown in Figure 9a. The adsorbed amount increased with the increasing of the initial concentration of $\mathrm{Ni}$ ions. When the initial concentration of $\mathrm{Ni}$ ions exceeded $52 \mu \mathrm{g} / \mathrm{L}$, the adsorption achieved equilibrium and the largest sorption amount was $50.1 \mathrm{mg} / \mathrm{g}$. Therefore, $52 \mu \mathrm{g} / \mathrm{L}$ of $\mathrm{Ni}$ ions was selected as the best initial concentration in the following experiment.
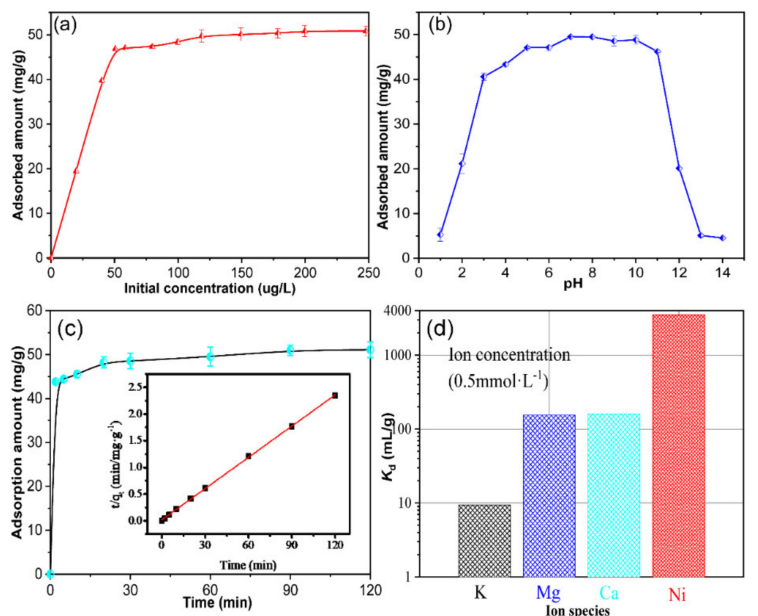

Figure 9. The bath experiment results. (a) The influence of the initial concentration on the adsorption of Ni ions; (b) The effect of $\mathrm{pH}$ on the adsorption of Ni ions; (c) The influence of the contact time on the adsorption of Ni ions; (d) The selective adsorption property of Ni from the multi-component aqueoussolution by the adsorbent. 
Figure $9 b$ shows the influence of the $\mathrm{pH}$ on the sorption amount of Ni. From Figure $9 \mathrm{~b}$, we can conclude that the sorption amount increased with the increasing $\mathrm{pH}$ from 1-6 and it maintained a slight change at the maximal sorption amount $(50.1 \mathrm{mg} / \mathrm{g})$ in the $\mathrm{pH}$ range from 6 to 10. When the $\mathrm{pH}$ was $>10$, the sorption amount rapidly decreased due to the low concentration of $\mathrm{Ni}$ species in the solution, which the $\mathrm{Ni}$ species transformed from $\mathrm{NiOH}^{+}$ to $\mathrm{Ni}(\mathrm{OH})_{2}$ precipitate (Figure 8). Besides, the low sorption amount in low $\mathrm{pH}$ region may be attributed to the reason that excessive hydrogen ions occupy the sorption sits on the adsorbent. Therefore, the $\mathrm{pH} \sim 8$ was selected as the optimal one in this study.

The influence of contact time is described in Figure 9c. Figure $9 \mathrm{c}$ shows that the sorption equilibrium was achieved within $30 \mathrm{~min}$, which presented a rather rapid adsorption ratio of $\mathrm{Ni}$ ions on the adsorbent. The fitting curve with the second-order dynamic model is illustrated in Figure 9c. It evidenced that the sorption process satisfied the second-order dynamic equation well and the fitted straight line.

The affinity and selectivity test results from multicomponent solutions are shown in Figure $9 \mathrm{~d}$. The $K_{d}$ values of the adsorbent toward $\mathrm{K}, \mathrm{Mg}$, Ca, and $\mathrm{Ni}$ in these experimental conditions were found to be $9.4,153.8,161.2$, and $3501.3 \mathrm{~mL} / \mathrm{g}$ respectively, which indicated a better affinity of the adsorbent toward $\mathrm{Ni}$ ions and the order was $\mathrm{Ni}^{2+}(9.4 \mathrm{~mL} / \mathrm{g})$, $\mathrm{Ca}^{2+}(161.2 \mathrm{~mL} / \mathrm{g}), \mathrm{Mg}^{2+}(153.8 \mathrm{~mL} / \mathrm{g}), \mathrm{K}^{+}(9.4 \mathrm{~mL} / \mathrm{g})$. Based on our knowledge [39], the hydrate species and valence state of metal ions in aqueous solution were also influenced by the sorption process on the adsorbent, as some metal ions are commonly removed from aqueous solutions by coprecipitation. As can be seen in Figure $9 \mathrm{~d}$, the low $K_{d}$ value of $\mathrm{K}$ can be mainly attributed to the low valence state (monovalence), while the relatively higher $K_{d}$ values of $\mathrm{Ca}$ and $\mathrm{Mg}$ are due to the higher valence state (divalent). The difference of the $K_{d}$ value between $\mathrm{Ni}$ and $\mathrm{Ca}, \mathrm{Mg}$ may be ascribed to the hydrated radius of $\mathrm{Ni}^{2+}$ being more appropriate than that of $\mathrm{Ca}^{2+}, \mathrm{Mg}^{2+}$ when considering the interlayer size of the adsorbent.

\subsection{Adsorption Data Simulation by Isothermal Adsorption Models}

To better understand the sorption process in dilute aqueous solution containing $\mathrm{Ni}$ ions, isothermal adsorption models such as Langmuir, Freundlich, and Redlich-Peterson isotherms sorption models were introduced to fit the sorption data and the equations are given as follows:

Langmuir Model [40-42]:

$$
q_{e}=\frac{q_{m} K_{L} C_{e}}{1+K_{L} C_{e}}
$$

where $q_{e}(\mathrm{mg} / \mathrm{g})$ is the equilibrium absorption capacity; $C_{e}$ is the equilibrium concentration of Ni ions in solution $(\mathrm{mg} / \mathrm{L}) ; q_{m}(\mathrm{mg} / \mathrm{g})$ is the estimated saturated adsorbed amount of the adsorbent; $K_{L}(\mathrm{~L} / \mathrm{mg})$ is the isothermal adsorption equation constant.

Freundlich Model [43]:

$$
q_{e}=K_{F} C_{e}^{1 / n}
$$

where $q_{e}(\mathrm{mg} / \mathrm{g})$ is the equilibrium absorption capacity; $C_{e}$ is the equilibrium concentration of $\mathrm{Ni}$ ions in solution $(\mathrm{mg} / \mathrm{L}) ; K_{F}$ is the sorption parameter, namely the distribution coefficient of nickel ions between aqueous phase and adsorbent; $\mathrm{n}$ is the constant.

Redlich-Peterson Model [44]:

$$
q_{e}=A C_{e} /\left(1+B C_{e}^{g}\right)
$$

where $q_{e}(\mathrm{mg} / \mathrm{g})$ is the equilibrium absorption capacity, $C_{e}$ is the equilibrium concentration of $\mathrm{Ni}$ ions in solution $(\mathrm{mg} / \mathrm{L}) ; A, B$ are the Langmuir-Freundlich parameters and $g$ is the Freundlich empirical parameter, which is between 0 and 1.

The nonlinear fitting results with those models are shown in Figure 10. The calculated equilibrium constants are summarized in Table 2. The correlation coefficient $\left(R^{2}\right)$ suggested that the Ni adsorption on the adsorbent could be well described by the Redlich-Peterson isotherms adsorption model, which may explain monolayer uniform adsorption with finite equivalent adsorption sites and multilayer adsorption on the heterogeneous surfaces which 
corresponded to the results in Figure 2b. The lower values of the correlation coefficient in the Langmuir and Freundich models evidenced that the Redlich-Peterson isotherms adsorption model was more suitable when used for describing the actual situation of solution adsorption. However, according to the complexity of the solid-liquid sorption, it should be noted that the Redlich-Peterson isotherms adsorption model could not completely describe the reaction mechanism of the complex system, where it can just be used as a method for processing experimental data.

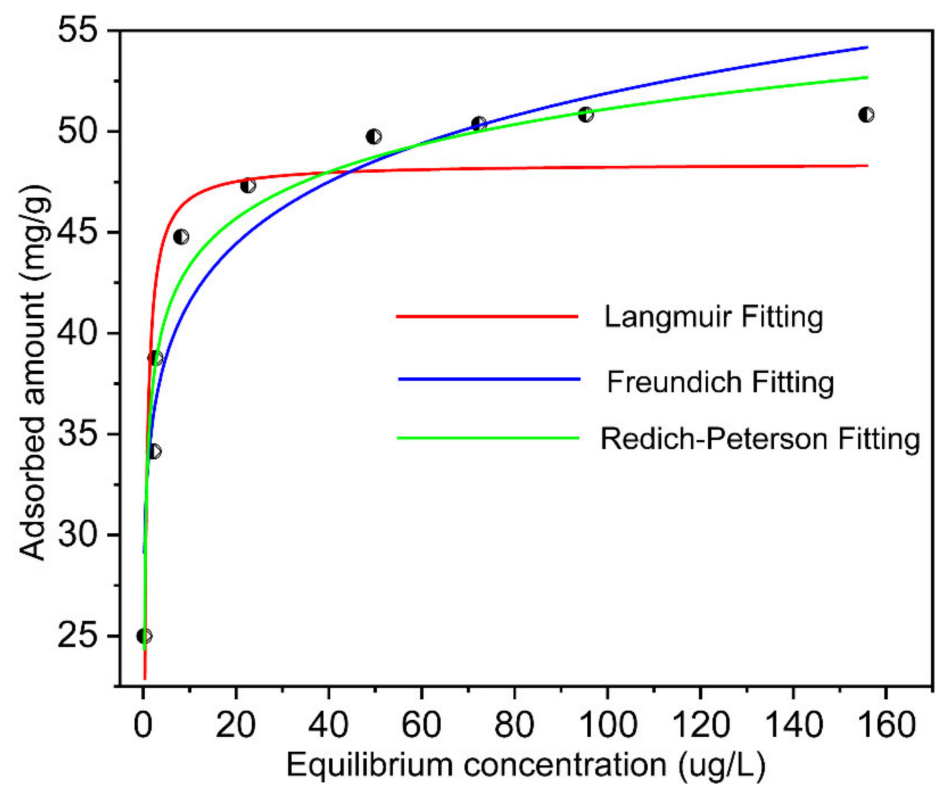

Figure 10. The nonlinear fitting results by Langmuir, Freundlich, and Redlich-Peterson isotherms sorption models.

Table 2. Ion-exchange adsorption constants obtained by fitting isotherm data with different Langmuir, Freundlich, and Redlich-Peterson models.

\begin{tabular}{ccccc}
\hline Isotherm Model & \multicolumn{4}{c}{ Estimated Isotherm Parameters } \\
\hline Langmuir & $K_{L} 2.7$ & $q_{m}(\mathrm{mg} / \mathrm{g}) 48.4$ & $R^{2} 0.82$ & \\
Freundlich & $K_{F} 33.3$ & $n 10.3$ & $R^{2} 0.91$ & \\
Redlich-Peterson & $A 327.3$ & $B 8.8$ & $g 0.93$ & $R^{2} 0.96$ \\
\hline
\end{tabular}

\subsection{Ni Ions Leaching and the Stability of the Adsorbent Test}

The leaching experiment was conducted by putting $0.1 \mathrm{~g}$ of the adsorbed adsorbent into $50 \mathrm{~mL}$ of $0.1 \mathrm{M} \mathrm{HCl}$ solution at room temperature and the leaching time was from 1 to 14 days. The leaching amount of $\mathrm{Ni}$ ions was measured by GFAAS and the results are shown in Figure 9. In addition, the leaching rate $(L)$ was obtained by the following Equation [44,45]:

$$
L=\frac{C_{t} * V}{q_{e} * m * 1000}
$$

where $q_{e}(\mathrm{mg} / \mathrm{g})$ is the equilibrium absorption capacity; $m$ is the mass of the adsorbent, $C_{t}(\mathrm{mg} / \mathrm{L})$ is the Ni concentration of the leachates at time $t$; and $V(\mathrm{~mL})$ is the volume of the leaching solution.

From Figure 11, we can see that the leaching ratio of Ni slightly increased with the contact time from 1 to 14 days. Nevertheless, the total leaching ratio did not exceed $0.4 \%$ of the mass of the adsorbent. These results evidenced a strong bonding interaction happening between $\mathrm{Ni}$ and the functional groups on the surface of the adsorbent, which 
indicated a chemical reaction occurred in the sorption process and the reaction process can be interpreted by the following Equation:

$$
\begin{gathered}
-\mathrm{Si}-\mathrm{Ti}-\mathrm{P}-\mathrm{Zr}-\mathrm{O}-+\mathrm{N}_{i}^{2+}=-\mathrm{Si}-\mathrm{Ti}-\mathrm{P}-\mathrm{Zr}-\mathrm{O}-\mathrm{Ni}- \\
-\mathrm{Si}-\mathrm{Ti}-\mathrm{P}-\mathrm{Zr}-\mathrm{O}-\mathrm{Ni}-+H^{+}=-\mathrm{Si}-\mathrm{Ti}-\mathrm{P}-\mathrm{Zr}-\mathrm{O}-\mathrm{H}+\mathrm{Ni}-
\end{gathered}
$$

To make sure the low leaching ratio of $\mathrm{Ni}$ ions was attributed to the chemical reaction between $\mathrm{Ni}$ ions and the hydroxy groups rather than the dissolving of the adsorbent in strong-acids solution, the stability property measurement of the adsorbent was also studied. Similar to the conditions in the leaching experiment, $0.1 \mathrm{~g}$ of the adsorbent was added into $50 \mathrm{~mL}$ of $0.1 \mathrm{M} \mathrm{HCl}$ solution at room temperature and the contact time was 14 days. Zirconium element was chosen, as the representative ions of the adsorbent and the concentration of $\mathrm{Zr}$ in the solution was measured by GFAAS. The GFAAS results of $\mathrm{Zr}$ ions showed that there were hardly any $\mathrm{Zr}$ ions in the solution, which indicated that the adsorbent was stable in a solution of strong acids and ensured that the leaching of $\mathrm{Ni}$ ions from the adsorbed adsorbent really originated from the reaction between $\mathrm{Ni}$ ions and hydrogen ions.

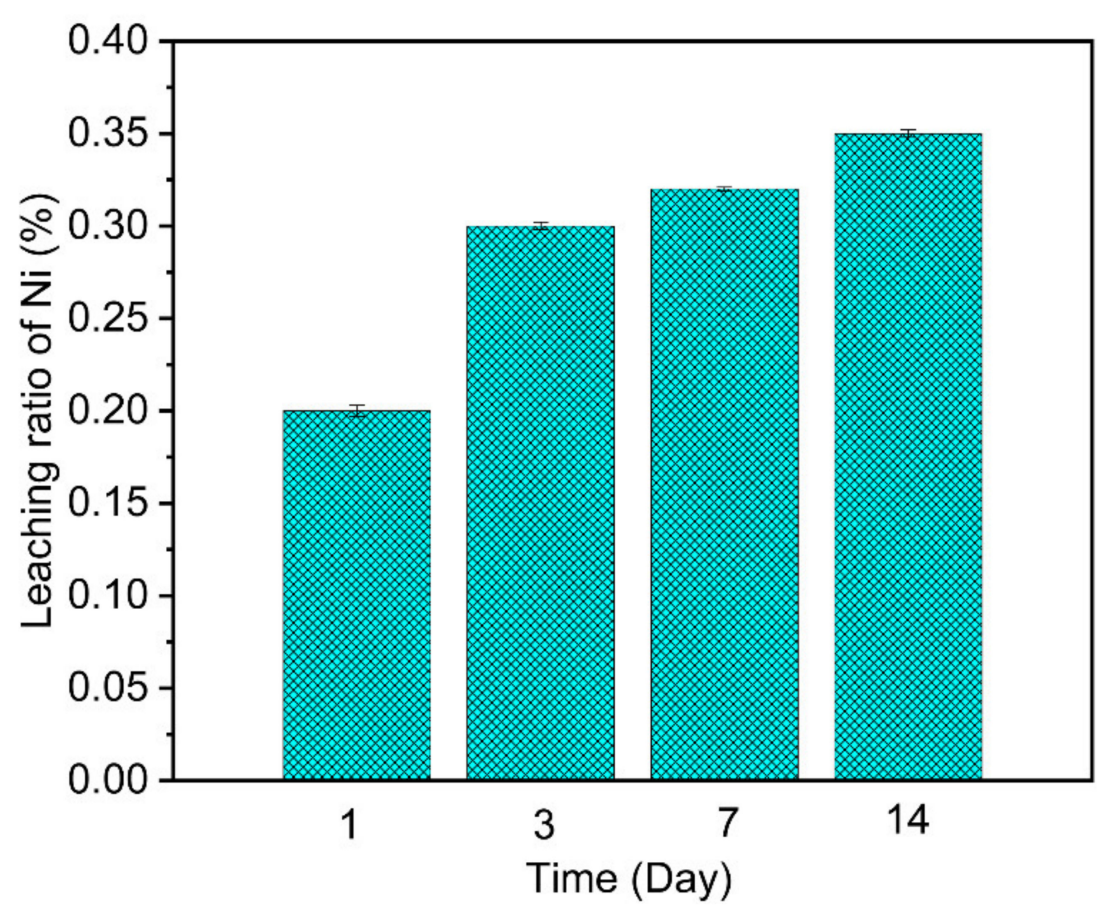

Figure 11. Leachability of Sr from sintered adsorbed Si-Ti-P-Zr adsorbent.

\section{Conclusions}

This study provided an excellent polymetallic phosphate adsorbent for effectively removing Ni ions from wastewater. The layer-by-layer method was firstly adopted to immobilize a useful metal phosphate adsorbent on the silica substrate which could not only significantly reduce the aggregation of the small particles, but also greatly enhance the hydraulic performance, mechanical endurance, and the abrasion resistance of the adsorbent. The Ni ions leaching and the stability of the adsorbent test indicated that the adsorbent synthesized in this paper possessed a stable ability for immobilizing $\mathrm{Ni}$ ions and a stable structure in the extreme acid condition, in which the total leaching ratio did not exceed $0.4 \%$ of the mass of the adsorbent within 14 days. The bath experiments revealed a fast (30 $\mathrm{min}$ ) and high adsorption amount $(50 \mathrm{mg} / \mathrm{g}$ ) of $\mathrm{Ni}$ ions from wastewater. Considering the affinity of the adsorbent to $\mathrm{Ni}$, the solution with a higher concentration of $\mathrm{K}, \mathrm{Mg}$, and $\mathrm{Ca}$ was used to test the affinity. The results evidenced that the composite processed higher 
affinity properties to $\mathrm{Ni}$ and the affinity order was $\mathrm{Ni}^{2+}>\mathrm{Ca}^{2+}>\mathrm{Mg}^{2+}>\mathrm{K}^{+}$. Besides, the introduction of the thermodynamic simulations of the hydrolyzed species of $\mathrm{Ni}$ ions in this study provided a better way to understand the sorption mechanism of $\mathrm{Ni}$ ions on the adsorbent due to that this method clearly exhibiting the different hydrolyzed species of $\mathrm{Ni}$ ions in various $\mathrm{pH}$ scopes (1-14). In conclusion, the silica-based zirconiumtitanium phosphate is a promising adsorbent for cleaning wastewater-containing diluted concentration of Ni ions.

Author Contributions: Conceptualization, C.L. and Y.Z.; methodology, C.L.; software, C.L.; validation, C.L., J.Z. and Y.Z.; formal analysis, J.Z.; investigation, C.L.; resources, C.L.; data curation, Y.Z.; writing—original draft preparation, C.L.; writing—review and editing, J.Z.; visualization, Y.Z.; supervision, C.L.; project administration, C.L.; funding acquisition, C.L. All authors have read and agreed to the published version of the manuscript.

Funding: This work was supported by the Liaocheng University High-level talents, Doctoral Research Start-up Fund (Grant number 318/318052050).

Conflicts of Interest: The authors declare no conflict of interest.

\section{References}

1. Humood, A.N. Assessment and management of heavy metal pollution in the marine environment of the Arabian Gulf: A review. Mar. Pollut. Bull. 2013, 72, 6-13.

2. Liu, H.Q.; Zhao, D.P.; Dai, M.Z.; Zhu, X.F.; Qu, F.Y.; Umar, A.; Wu, X. PEDOT decorated CoNi $\mathrm{S}_{4}$ nanosheets electrode as bifunctional electrocatalyst for enhanced electrocatalysis. Chem. Eng. J. 2021, 428, 131183. [CrossRef]

3. Al-Attar, A.M. Vitamin E attenuates liver injury induced by exposure to lead, mercury, cadmium and copper in albino mice. Saudi. J. Biol. Sci. 2011, 18, 395-401. [CrossRef]

4. Wang, C.; Li, T.; Yu, G.; Deng, S.B. Removal of low concentrations of nickel ions in electroplating wastewater using capacitive deionization technology. Chemosphere 2021, 248, 13141.

5. Aggarwal, D.A.; Goyal, M.; Bansal, R.C. Adsorption of chromium by activated carbon from aqueous solution. Carbon 1999, 37, 1989-1997. [CrossRef]

6. Carboni, M.C.; Abney, W.; Liu, S.; Lin, W. Highly porous and stable metal-organic frameworks for uranium extraction. Chem. Sci. 2013, 4, 2396-2402. [CrossRef]

7. Wang, L.L.; Luo, F.; Dang, L.L.; Li, J.Q.; Wu, X.L.; Liu, S.J.; Luo, M.B. Ultrafast high-performance extraction of uranium from seawater without pretreatment using an acylamide-and carboxyl-functionalized metal-organic framework. J. Mater. Chem. A 2015, 3, 13724-13730. [CrossRef]

8. Yang, W.T.; Bai, Z.Q.; Shi, W.Q.; Yuan, L.Y.; Tian, T.Z.; Chai, F.; Wang, H.; Sun, Z. MOF-76: From a luminescent probe to highly efficient U(VI) sorption material. Chem. Commun. 2013, 49, 10415-10417. [CrossRef]

9. Grabias, E.; Gladysz, P.A.; Ksiazek, A.; Majdan, M. Efficient uranium immobilization on red clay with phosphates. Environ. Chem. Lett. 2014, 12, 297-301. [CrossRef]

10. Misaelides, P.; Godelitsas, A.; Filippidis, A.; Charistos, D.; Anousis, I. Thorium and uranium uptake by natural zeolitic materials. Sci. Total Environ. 1995, 173, 237-246. [CrossRef]

11. Attar, L.A.; Dyer, A. Sorption behaviour of uranium on birnessite, a layered manganese oxide. J. Mater. Chem. 2002, 12, 1381-1386. [CrossRef]

12. Starvin, A.M.; Rao, T.P. Solid phase extractive preconcentration of uranium (VI) onto diarylazobisphenol modified activated carbon. Talanata 2004, 63, 225-232. [CrossRef]

13. Ulusoy, H.I.; Simsek, S. Removal of uranyl ions in aquatic mediums by using a new material: Gallocyanine grafted hydrogel. $J$. Hazard. Mater. 2013, 254, 397-405. [CrossRef]

14. Yue, Y.F.; Mayes, R.T.; Kim, J.P.; Fulvio, F.; Sun, X.G.; Tsouris, C.; Chen, J.H.; Brown, S.; Dai, S. Seawater uranium sorbents: Preparation from a mesoporous copolymer initiator by atom transfer radical polymerization. Angew. Chem. Int. Ed. 2013, 52, 13458-13462. [CrossRef] [PubMed]

15. Li, B.; Rong, T.L.; Du, X.Y.; Shen, Y.Y.; Shen, Y.Q. Preparation of $\mathrm{Fe}_{3} \mathrm{O}_{4}$ particles with unique structures from nickel slag for enhancing microwave absorption properties. Ceram. Int. 2021, 47, 18848-18857. [CrossRef]

16. Kumar, N.; Singh, R.K.; Kumar, S.; Kumar, P. Tuning in optical, magnetic and Curie temperature behaviour of nickel ferrite by substitution of monovalent $\mathrm{K}^{+1}$ ion of $\mathrm{Ni}_{0.8} \mathrm{~K}_{0.2} \mathrm{Fe}_{2} \mathrm{O}_{4}$ nanomaterials for multifunctional applications. Phys. B 2021, 606, 412797 . [CrossRef]

17. Mellah, A.; Chegrouche, S.; Barkat, M.J. The removal of uranium (VI) from aqueous solutions onto activated carbon: Kinetic and thermodynamic investigations. Colloid Interface. Sci. 2006, 296, 434-441. [CrossRef]

18. Murphy, B.; Murphy, C.; Hathway, B.J. The Lewis structures of molecules, cations and anions, including oxyanions. Saudi J. Biol. Sci. 2001, 18, 395-401. 
19. Kurniawan, T.A.; Chan, G.Y.S.; Lo, W.H.; Babel, S. Physico-chemical treatment techniques for wastewater laden with heavy metals. Chem. Eng. J. 2006, 118, 83-98. [CrossRef]

20. Thakkar, R.; Chudasama, U. Synthesis and characterization of zirconium titanium phosphate and its application in separation of metal ions. J. Hazard. Mater. 2009, 172, 129-137. [CrossRef]

21. Baneto, M.; Enesca, A.; Mihoreanu, C.; Lare, Y.; Jondo, K.; Napo, K.; Duta, A. Effects of the growth temperature on the properties of spray deposited CuInS 2 thin films for photovoltaic applications. Ceram. Int. 2015, 41, 4742-4749. [CrossRef]

22. Khan, A.A.; Paquiza, L. Electrical behavior of conducting polymer based 'polymeric-inorganic' nanocomposite: Polyaniline and polypyrrole zirconium titanium phosphate. Synthetic Met. 2011, 161, 899-905. [CrossRef]

23. Pan, B.C.; Zhang, Q.R.; Du, W.; Zhang, W.M.; Pan, B.J.; Zhang, Q.J.; Xu, Z.W.; Zhang, Q.X. Selective heavy metals removal from waters by amorphous zirconium phosphate: Behavior and mechanism. Water. Res. 2007, 41, 3103-3111. [CrossRef]

24. Poojary, D.; Shpeizer, M.B.; Clearfield, A.J. Chem, Synthesis and x-ray powder structures of two lamellar copper arylenebis (phosphonates). Soc. Dalton. Trans. 1996, 35, 4942-4949.

25. Bruque, S.; Aranda, M.A.G.; Losilla, E.R.; Olivera, P.P.; Maireles, T.P. Synthesis Optimization and Crystal Structures of Layered Metal (IV) Hydrogen Phosphates alpha-M $\left(\mathrm{HPO}_{4}\right)_{2}$. cntdot. $\mathrm{H}_{2} \mathrm{O}(\mathrm{M}=\mathrm{Ti}$, Sn, Pb). Inorg. Chem. 1995, 34, 893-899. [CrossRef]

26. Ekambaram, S.; Sevov, S.C. Organically Templated Mixed-Valent $\mathrm{Ti}^{\mathrm{III}} / \mathrm{Ti}^{\mathrm{IV}}$ Phosphate with an Octahedral-Tetrahedral Open Framework. Angew. Chem. Int. Ed. 1999, 38, 372-380. [CrossRef]

27. Yu, J.H.; Xu, R.R. Insight into the construction of open-framework aluminophosphates. Soc. Rev. 2006, 35, 593-601. [CrossRef] [PubMed]

28. Burnell, V.A.; Readman, J.E.; Tang, C.C.; Parker, J.E.; Thompson, S.P.; Hriljac, J.A. Synthesis and structural characterisation using Rietveld and pair distribution function analysis of layered mixed titanium-zirconium phosphates. J. Solid State Chem. 2010, 183, 2196-2204. [CrossRef]

29. Liu, X.Y.; Gao, J.W.; Wang, Q.M. Structural-property correlations of all-inorganic $\mathrm{CsPbB}_{3}$ perovskites via synergetic controls by $\mathrm{PbBr}$, 2-mercapto-3-methyl-4-thiazoleacetic acid and water. Chem. Eng. J. 2021, 428, 131117. [CrossRef]

30. Zhang, J.N.; Ma, Z.; Jiao, J.; Yin, H.F.; Yan, W.F.; Hagaman, E.W.; Yu, J.H.; Dai, S. Layer-by-Layer Grafting of Titanium Phosphate onto Mesoporous Silica SBA-15 Surfaces: Synthesis, Characterization, and Applications. Langmuir 2009, 25, 12541-12549. [CrossRef] [PubMed]

31. Zhao, D.Y.; Huo, Q.S.; Feng, J.L.; Chmelka, B.F.; Stucky, G.D. Nonionic Triblock and Star Diblock Copolymer and Oligomeric Surfactant Syntheses of Highly Ordered, Hydrothermally Stable Mesoporous Silica Structures. J. Am. Chem. Soc. 1998, 120, 6024-6036. [CrossRef]

32. Li, C.M.; Zhang, Y.S.; Wang, X.P.; Yin, X.B.; Luo, N.N.; Fshin, K.A.; Wei, Y.Z. The synthesis and characterization of hydrous cerium oxide nanoparticles loaded on porous silica micro-sphere as novel and efficient adsorbents to remove phosphate radicals from water. Micropor. Mesopor. Mat. 2019, 279, 73-81. [CrossRef]

33. Tang, Q.; Wang, K.T.; Muhammad, Y.; Tong, Z.F.; Cui, X.M. Synthesis of highly efficient porous inorganic polymer microsphere for adsorptive removal of $\mathrm{Pb}^{2+}$ from wastewater. J. Clean. Prod. 2018, 193, 351-362. [CrossRef]

34. Gupta, A.; Yunus, M.; Sankararamakrishnan, N. Zerovalent iron encapsulated chitosan nanospheres-a novel adsorbent for the removal of total inorganic arsenic from aqueous systems. Chemosphere 2012, 86, 150-155. [CrossRef]

35. Li, C.M.; Wei, Y.Z.; Wang, X.P.; Yin, X.B. Efficient and rapid adsorption of iodide ion from aqueous solution by porous silica spheres loaded with calcined Mg-Al layered double hydroxide. J. Taiwan Inst. Chem. Eng. 2018, 85, 193-200. [CrossRef]

36. Zhang, Q.R.; Du, Q.; Jiao, T.F.; Pan, B.C.; Zhang, Z.X.; Sun, Q.N.; Wang, S.; Wang, F.T.; Gao, F.M. Selective removal of phosphate in waters using a novel of cation adsorbent: Zirconium phosphate (ZrP) behavior and mechanism. Chem. Eng. J. 2013, 221, 315-321. [CrossRef]

37. Thakkar, R.; Chudasama, U. Synthesis, characterization and proton transport properties of a mixed material-Zirconium titanium phosphate, a tetravalent bimetallic acid salt. Electrochim. Acta 2009, 54, 2720-2726. [CrossRef]

38. Liu, C.C.; Chen, L.F.; Ye, Z.X.; Li, C.M.; Yin, X.B.; Wang, X.P.; Wei, Y.Z. Pellet silica-based titanate adsorbents with high selectivity for strontium removal from synthetic radioactive solutions. J. Sol-Gel Sci. Technol. 2019, 91, 273-285. [CrossRef]

39. Soner, A.H.; Sema, A.; Fikret, T. Arsenic removal from aqueous solutions by adsorption on red mud. Waste Manag. 2000, 20, 761-767. [CrossRef]

40. Low, K.S.; Lee, C.K. Chrome waste as sorbent for the removal of arsenic (V) from aqueous solution. Environ. Technol. 1995, 16, 65-71. [CrossRef]

41. Chinnaiya, N.; Sadasivam, S. Removal of arsenic (V) from aqueous solution using industrial sold waste: Adsorption rates and equilibrum studies. Ind. Eng. Chem. Res. 1998, 37, 4816-4822.

42. Jossens, L.; Prausnitz, J.M.; Fritz, W. Thermodynamics of multi-solute adsorption from dilute aqueous solutions. Chem. Eng. Sci. 1978, 33, 1097-1106. [CrossRef] 
43. Delhia, A.; Clarence, C.; Marc, H.; Bénédicte, P.; Jerzy, Z. Recent developments in nanostructured inorganic materials for sorption of cesium and strontium: Synthesis and shaping, sorption capacity, mechanisms, and selectivity-A review. J. Hazard. Mater. 2018, 344, 511-530.

44. Ikarashi, Y.; Mimura, H.; Nakai, T.; Niibori, Y.; Ishizaki, E.; Matsukura, M. Selective cesium uptake behavior of insoluble ferrocyanide loaded zeolites and development of stable solidifcation method. J. Ion Exch. 2014, 25, 212-219. [CrossRef]

45. Li, C.M.; Liu, C.C.; Chen, L.F.; Ye, Z.X.; Zhang, Y.S.; Wang, X.P.; Wei, Y.Z. Studies on the separation and in-situ sintering solidifcation of strontium by a highly-efcient titanate-based adsorbent. Micropor. Mesopor. Mater. 2019, 288, 109607. [CrossRef] 